\title{
Is Weekly Frequency of Yoga Practice Sufficient? Physiological Effects of Hatha Yoga Among Healthy Novice Women
}

\author{
Barbara Csala ${ }^{1,2 *}$, Renáta Szemerszky ${ }^{2}$, János Körmendi ${ }^{1,2}$, Ferenc Köteles ${ }^{2 \dagger}$ and \\ Szilvia Boros ${ }^{2 \dagger}$ \\ ${ }^{1}$ Doctoral School of Psychology, ELTE Eötvös Loránd University, Budapest, Hungary, ${ }^{2}$ Institute of Health Promotion and \\ Sport Sciences, ELTE Eötvös Loránd University, Budapest, Hungary
}

OPEN ACCESS

Edited by:

Nilkamal Singh,

Manipur University, India

Reviewed by:

Charles F. Harrington, University of South Carolina Upstate,

United States

Laszlo Toth

University of Physical

Education, Hungary

${ }^{*}$ Correspondence:

Barbara Csala

csala.barbara@ppk.elte.hu

these authors share senior authorship

Specialty section:

This article was submitted to Public Health Education and

Promotion,

a section of the journal

Frontiers in Public Health

Received: 29 April 2021 Accepted: 21 September 2021

Published: 18 October 2021

Citation:

Csala B, Szemerszky R, Körmendi J, Köteles $F$ and Boros S (2021) Is Weekly Frequency of Yoga Practice Sufficient? Physiological Effects of Hatha Yoga Among Healthy Novice

Women.

Front. Public Health 9:702793. doi: 10.3389/fpubh.2021.702793
Beneficial physical and physiological health outcomes of yoga practice are well-supported by empirical data. However, whether weekly frequency of training is sufficient to evoke positive changes, is still an open question. The present intervention study investigated the effects of 10 weekly sessions of beginner level hatha yoga with respect to indicators of physical fitness and physiological markers. 82 young women (mean age of $22.0 \pm 3.83$ years) participated in the study. The yoga group ( $N=49$ ) attended a yoga course consisting of 10 sessions ( $1.5 \mathrm{~h}$ each) on a weekly basis. The control group $(N=33)$ did not receive any intervention. BMl, body fat percentage, balance (one-leg-stand test with open and closed eyes, functional reach test), flexibility (side bend test, modified sit and reach test) core muscle strength (plank test) as well as resting heart rate $(\mathrm{HR})$, and heart rate variability $(\mathrm{HRV})$ were assessed 1 week before and after the course. Both frequentist and Bayesian analysis showed an improvement in flexibility and balance in the yoga group compared to the control group. The yoga group showed also increased core muscle strength. No changes with respect to BMl, body fat percentage, resting HR and HRV were found. Ninety minute beginner level hatha yoga classes were characterized by $93.39 \mathrm{HR}$ and $195 \mathrm{kcal}$ energy consumption on average. The present findings suggest that weekly setting of a 10-session long hatha yoga training leads to improvements in balance, flexibility and core muscle strength among healthy young women. However, for changes in BMl, body fat percentage, resting HR and HRV longer, and/or more intense interventions are needed.

Keywords: hatha yoga, BMI, flexibility, balance, core strength, heart rate, heart rate variability

\section{INTRODUCTION}

Yoga is a complex philosophy and methodology which evolved over thousands of years in ancient India $(1,2)$. According to traditional definition as it is described in the famous Yoga Sutras of Patanjali, "Yogaschitta vrtti nirodhah" [(3), p. 31] which means that yoga is stopping the fluctuations/patterns of the mind. For a scientifically more clear definition of yoga, we can describe it as a path of self-realization which provides a holistic teaching, a complete view of life and a practical path for this sake (1, 4-9). Yoga comprises various physical, mental, moral, and spiritual practices which facilitate holistic health, 
well-being, and higher level of awareness (2, 4-10). There are various paths of yoga, however, the majority of the yoga classes offered in the West are body-focused practices which fall under the umbrella of hatha yoga (11). The practice of hatha yoga includes physical postures (asana), breathing exercises (pranayama), relaxation, and sometimes also meditation techniques $(2,12)$. It differs from other forms of physical exercise in many ways: it possesses specific body postures including relaxation poses, breath regulation, longer maintenance of the postures, furthermore, it requires constant non-judgmental attention during practice (4, 7, 13-15). Among these, breath regulation and constant awareness during practice are features of other mind-body exercises $(16,17)$ and other Eastern movement forms (such as aikido or karate) $(18,19)$.

During the last three decades, research on yoga has gained momentum, mainly due to its positive effects on health (17, 20,21). Reviews and comparison studies indicate that regular yoga practice has beneficial effects on various aspects of mental and physical health $(10,13,22-24)$. Yoga appears to be a valid method to improve physical and mental functioning in healthy populations, and it also offers therapeutic effects for a wide variety of pathological physical and psychological conditions $(13,22,25,26)$. Concerning physical fitness and cardiovascular characteristics, review studies mainly report positive outcomes in terms of flexibility, balance, strength, weight loss, blood pressure, respiration, heart rate, and overall cardiovascular endurance (10, 21-23, 27).

Regarding body weight and body mass index (BMI), a randomized controlled pilot study (28) investigated adults with high risk of diabetes. According to the outcomes, the yoga group showed reduced body weight and BMI at the end of the 8-week long (3-6 days/week, $75 \mathrm{~min} / \mathrm{session}$ ) intervention compared to the monitored walking group (28). Similarly, another study investigating healthy adults (29) reported a significant decrease in BMI after a 1-month long daily ( $1 \mathrm{~h})$ yoga training compared to the control group which received no intervention. A recent study (30) found significant decrease in body weight, BMI, and body fat percentage after a 1 week daily $(1.5 \mathrm{~h})$ yoga practice among overweight adults. However, yoga practice was accompanied by dietary advisement. In contrast, Tran et al. (31) did not found a significant change in body fat among healthy young adults after an 8 -week long ( 2 times/week, $1.5 \mathrm{~h} /$ session) yoga course.

A systematic review (32) summarized the effects of yoga practice on balance in healthy samples including participants from school children to elder adults. Out of 15 papers, 11 reported positive findings, especially in static balance. A later study (33) investigated middle-aged women participating in a power yoga program over 12 weeks (3 times/week, $1 \mathrm{~h} /$ session). Improvements in balance (both with open and closed eyes) and muscle (grip and back muscle) strength were found. Additionally, participants showed positive changes in body composition but no difference in BMI (33). Another study (34) investigated male college athletes. For 10 weeks, yoga participants attended two yoga classes per week ( $1 \mathrm{~h} /$ session) which were conducted before their usual sport training. The yoga group showed significant improvements in balance (measured by the stork stand test) and flexibility (assessed by the sit and reach test, shoulder flexibility, and joint angles measurements), while no significant changes in the control group were found (34).

Concerning further results on flexibility, middle-aged women showed a significant improvement in pliability (measured by the sit and reach test) after a 6-week long weekly (1.5 h/session) Iyengar yoga training (35). Betterment in flexibility (recorded by modified sit and reach test and trunk and neck extension test) were found also among adult male participants after a 12 week long (6 days/week, $1 \mathrm{~h}$ /session) hatha yoga training (36). In addition to the favorable changes in flexibility, increased muscle strength (grip and back), and decreased body weight and fat percentage were shown (36).

Beneficial effects of yoga practice on muscle strength were reported in some of the above-mentioned studies $(22,33,36)$; however, core muscle strength was not investigated by any of them. A comprehensive review (37) examining the impact of yoga practice on core muscle strength indicated that yoga practice, more precisely some simple yoga exercises have a great relevance in strengthening core muscles. Kumar et al.'s results (38) showed a significant improvement in core muscle strength assessed by the plank test after a 21-day long hatha yoga training among healthy adults (38). Similar positive outcomes were reported in two recent studies $(39,40)$.

Regarding cardiovascular effects such as heart rate (HR) and heart rate variability (HRV) results are equivocal. HR and HRV (variable beat-to-beat fluctuation in HR) are sensitive and easily captured indicators of autonomic regulation and vagal activity. High frequency (HF) components of HRV are considered an index of parasympathetic activity, while low frequency (LF) components of HRV are often related to sympathetic activity. However, interpretation of LF band is controversial $(41,42)$. Bidwell et al. (43) found no significant differences in resting $\mathrm{HR}$ and HF and LF components of HRV between the yoga and the control group after a 10-week long (2 times/week, 1 $\mathrm{h} /$ session) hatha yoga intervention among women with asthma (43). In contrast, a systematic review (44) reported an evidence of decreased HR in both healthy and high risk populations based on studies with yoga interventions of diverse length and intensity. According to a comprehensive review on yoga and HRV (42), the vast majority of the studies investigated the acute effects of yoga practice on HRV, and indicated an increased HRV and vagal dominance (HF) during practice. Regular yoga practitioners showed increased vagal tone (HF) at rest compared to non-yoga practitioners. However, the authors advised not to draw a final conclusions on the impact of yoga on HRV (42). Two recent studies $(45,46)$, nevertheless, also reported positive outcomes. Breast cancer patients showed improved HRV values at end of a 12-month long (3 times/week, 40-60 min/session) yoga training. These results were also significantly better than those of a Pilates control group (46). Similarly, patients with rheumatoid arthritis showed improved HRV values after a 12-week long (3 times/week, $30 \mathrm{~min} /$ session) yoga practice compared to the only medical treatment control group (45).

As presented above, there is a growing body of empirical evidence regarding the beneficial physical health impacts of yoga practice. Nonetheless, due to the diversity in research, generalization and standardization of the reported findings is 
a challenging task $(11,17)$. Several authors have signified that heterogeneity of yoga interventions make the comparison of the outcomes and the exploration of the particular effects of specific components and aspects of yoga practice among various populations difficult $(11,17,22,47)$. Yoga interventions should be described in more detail with respect to dosage and frequency of practice, type and components of yoga, and duration and location (context) of practice. It is also suggested to include information about the yoga instructor, the presence or extent of home practice, and any other potential biases and disturbing factors (47). Studies that address these methodological issues would enhance the likelihood of developing more adequate prevention, intervention, and rehabilitation programs for various populations $(10,22,48)$.

As presented above, most of the papers reported favorable outcomes concerning physical fitness and cardiovascular measures. Nevertheless, almost all of these studies involved yoga trainings with at least biweekly frequency, or often with (almost) daily practice. However, we have less accurate knowledge whether weekly frequency of yoga practice can result in improvements of physical fitness and heart rate characteristics among healthy adults. Previous studies involving one yoga class per week for 10 weeks showed significant improvements in mental health, physical and social functioning, and cognitivebehavioral performance among various adult samples (49-51). A recent study (52) with the same yoga intervention setting showed an increase in the right hippocampal density in healthy young adults when compared to active and passive controls. In an earlier study which applied a Pilates-training on a weekly basis for 10 weeks, Pilates participants showed improvements in flexibility, balance, and core- and abdominal muscle strength compared to no intervention controls (53). The authors proposed that a one-time per week training might be sufficient to evoke beneficial outcomes for healthy young women with a sedentary lifestyle.

According to a specific shortage of the empirical findings, aim of the present study was to investigate whether weekly frequency of beginner level hatha practice is sufficient to evoke beneficial changes in indicators of physical fitness and heart rate measures among healthy female adults. It was examined whether a 10session long, one time/week yoga training (with an emphasis on asana practice) can positively effect on body mass index (BMI), body fat percentage, balance, flexibility, core muscle strength, resting heart rate, and heart rate variability. Additionally, we intended to explore the training effect characteristics, namely $\mathrm{HR}$ and used calories during practice, of an average beginner level hatha yoga class.

\section{MATERIALS AND METHODS}

\section{Participants}

Beginner level hatha yoga training and courses for control participants were announced on the university's online registration platform. Only female students were eligible in order to avoid potential gender effects. Yoga groups included a maximum of 14 people. Control participants were aware of receiving no intervention; however, they were rewarded with credits for the participation and could become aware of their physical fitness during measurements, similarly to the yoga intervention participants. To avoid various confounding factors, the following inclusion criteria were applied for each group: no known psychiatric diagnosis; no prior experience with yoga; commitment to maintain current regular physical activity level and not to begin any new body focus related practices (such as relaxation or meditation) throughout the study. Also, in order to control the exact amount of yoga practice, approval of avoiding self-practice or any guided yoga techniques (e.g., recordings or videos) at home was needed. Overall, 115 students were enrolled in the study, 74 students in the yoga group and 41 participants in the control group. Due to drop-out, missing measurements or missing more than two yoga classes in case of the yoga group, the eventual sample included 82 participants (mean age: $22.0 \pm 3.83$ years). The yoga group consisted of 49 individuals (mean age: $21.49 \pm 2.3$ years), the control group comprised 33 participants (mean age: $22.75 \pm 5.32$ years). Average age and degree level (measured by the level of degree of the current studies) of the two groups were statistically comparable (age: $d=-1.29 ; p$ $=0.204$; degree: yoga: $1.20 \pm 0.41$, control: $1.36 \pm 0.49 ; d=$ $-1.55 ; p=0.127$ ). Average physical activity level in the previous 3 months (measured by a 5 -point rating scale: $1=$ no regular participation in physical activities, only occasionally; $3=2-3 \mathrm{~h}$ per week; $5=$ competes in sports or has at least five highintensity workouts per week) was also statistically comparable in the two groups (yoga: $1.84 \pm 1.2$, control: $2.24 \pm 1.23$ years; $d$ $=-1.48 ; p=0.142)$. Students were mostly engaged in running, spinning, aerobic, and fitness training; none of the groups were physically inactive.

At the beginning of the program, informed consent form was signed by each participant. The research was permitted by the Research Ethics Committee of the university.

\section{Procedure}

Data collection lasted for three semesters. After registration, participants received information via e-mail about the appointments for physical measurements and the conditions of attendance. Measurements were taken 1 week before and 1 week after the yoga course at the Institute of Health Promotion \& Sport Sciences of the university. Plank test, measured at the beginning of the first and last yoga class, was an exception; therefore, these data were not available for the control group.

The yoga course encompassed 10 weekly sessions, $1.5 \mathrm{~h}$ each. Control participants did not receive any training or alternative intervention, they took part solely in the baseline and postintervention measurements. Yoga classes had an emphasis on asana practice; all types of poses were included, namely sitting, standing, balancing poses, kneeling, forward and backward bends, supine and prone positions, and inversions. Classes always started with a short body and breath scan and ended with a relaxation practice of $8-10 \mathrm{~min}$ in Savasana (the lying corpse position). Scripts for the sessions were prepared according to two highly valued yoga books $(2,54)$. These were prepared before the course and strictly followed by the yoga instructor, namely a certified (RYT500) female yoga teacher (BC, one of the authors), throughout all groups and all semesters (see Appendix for class plan). 
The complete study also included psychological measurements in which two yoga groups were differentiated. However, those did not differ in any aspects, thus were merged together. Results of psychological outcomes are reported in another paper (55).

\section{Measures}

$B M I$ was calculated from the assessed body weight and height data. Body weight and body fat percentage was measured with OMRON BF-511 body composition scale (OMRON Healthcare Group, Kyoto, Japan) using given height, gender, and age data.

Static balance was measured both with open and closed eyes by the one-leg-stand (stork) test (56).The task is to hold a stand on one foot with placing the heel of the opposite foot on the inside of the standing leg at knee level. The test lasts for $60 \mathrm{~s}$ while the number of errors, namely off-balance situations are recorded: the movement of the standing leg or loss of contact of the upper leg with the standing leg. The test was measured once with open and then with closed eyes. Functional reach test (FRT) (57) also assesses static balance. A maximal stable forward reach is needed to be performed from a fixed standing start position with one arm extending forward. Difference between the arm's length and the measured maximal forward reach $(\mathrm{cm})$ is calculated. Better result of two trials is recorded.

Flexibility was investigated by the side bend test and the modified sit and reach test. The side bend test (58) measures pliability of the thoracic and lumbar part of the back. The starting pose is standing straight with shoulders, scapulae, and head touching the wall. The participant is asked to bend to one side keeping his/her hands straight at the thighs. Difference between the starting and ending point at the tip of the middle finger sliding down along the thigh is calculated in $\mathrm{cm}$. There is one bend to each side, average of the two sides were calculated as a final variable. The modified sit and reach test (59) assesses the flexibility of hip region, involving the lower back and hamstring muscles. This modified version of the test aims to control for the variable ratio of the length of the limbs and the trunk. The test person sits with head, back, and shoulders at the wall, measurement box is placed to his/her feet. Legs are straight with hip apart. To measure the start position, the performer reaches out with hands placed on each other while the back and the head stay in touch with the wall. Then, the person bends forward at maximum level with sliding the hands on the top of the box. Difference between the starting point and the end reach at the tip of the middle finger is recorded $(\mathrm{cm})$.

Plank test (60) measures the muscular endurance of core muscles. Participant's task is to hold a forearm plank pose keeping a straight body position. Only forearms and toes are supported on the ground. Aim is to hold the position as long as possible. Time was recorded in seconds with a maximal length of $120 \mathrm{~s}$.

Heart rate and heart rate variability data were collected with Firstbeat Teambelt system from FirstBeat SPORTS Team Pack (Firstbeat Technologies Ltd., Jyväskylä, Finland) (61). A chest belt was attached to the participant ribcage who was asked to sit quietly without any movements. The belt includes two built-in electrodes and a wireless unit transmitting data to a receiver on a computer in real time. The sampling rate is $1,024 \mathrm{~Hz}$. Resting heart rate data were collected for $5 \mathrm{~min}$ and analyzed by the Firstbeat Sports software. Two measures were extracted: resting heart rate, that is $r H R(b p m)$ and RMSSD (ms), i.e., the root mean square of successive differences of interval. It is considered an index of parasympathetic activation of heart $(42,62,63)$.

Firstbeat Teambelt system was also used during yoga practice to measure participants average heart rate $(A v g H R)$ and energy consumption $(\mathrm{kcal})$ during the 90 -min-long classes. An average from all participated classes was calculated as a final value for both variables.

\section{Data Analysis}

Statistical analysis was conducted with the help of JASP v0.12.2 software (64). To test the homogeneity of the two groups at beginning, Welch d-tests were applied for all measures. The potential effect of the intervention was calculated by $2 \times 2$ mixed ANOVA (time $x$ intervention) for each variable with the exception of plank test. For that, due to missing control data, paired sample $t$-test was applied. Respective effect sizes were calculated for all tests. The sample size varies across the variables due to lacking or invalid data at particular measures.

Beyond the conventional frequentist analysis, Bayesian tests were also conducted to shed more light on non-significant results. Bayes factor $\left(\mathrm{BF}_{10}\right)$ shows the likelihood of an alternative hypothesis compared to the null hypothesis. If $\mathrm{BF}_{10}$ is smaller than 0.33 , the null hypothesis is more probable than the alternative one. In contrast, $\mathrm{BF}_{10}$ above 10 indicates a strong support for the alternative hypotheses. $\mathrm{BF}_{10}$ values between 1 and 3 suggest only a weak or anecdotal indication for the alternative hypothesis (65). To avoid the well-known limitations of the classic frequentist statistics (those related to Type 1 and 2 errors), many authors have recommended the usage of Bayesian analysis as it provides a more precise answer to research questions compared to the frequentist one (65-67).

\section{RESULTS AND DISCUSSION}

\section{Results}

Descriptive data of the measured physical and physiological variables in the two groups, and baseline comparisons are presented in Table 1. No significant differences between the groups emerged for any variables at baseline.

Results of the $2 \times 2$ mixed ANOVAs for the physical variables are presented in Table 2.

There were no significant interactions for BMI, BodyFat $\%$, one-leg-stand with closed eyes and FRT. In fact, Bayesian analysis showed the dominance of the null model for these variables. However, a significant interaction term emerged for one-legstand with open eyes, side bend test, and sit and reach test. Values of these three variables improved in the yoga group, while they declined in the control group. These outcomes were strongly supported by those of the Bayesian analysis with $\mathrm{BF}_{10}$ values over 10. In case of sit and reach, $\mathrm{BF}_{10}$ over 1,000 shows a saliently strong support. Concerning the plank test, paired sample $t$-test showed a significant result $\left[t_{(32)}=-5.963 ; p<0.001\right.$; Cohen's $d=-1.038$ ) which was also well-supported by the Bayesian analysis $\left(\mathrm{BF}_{10}=14647.622\right)$. 
TABLE 1 | Descriptive data of the assessed variables before and after the intervention, and baseline comparison of the groups.

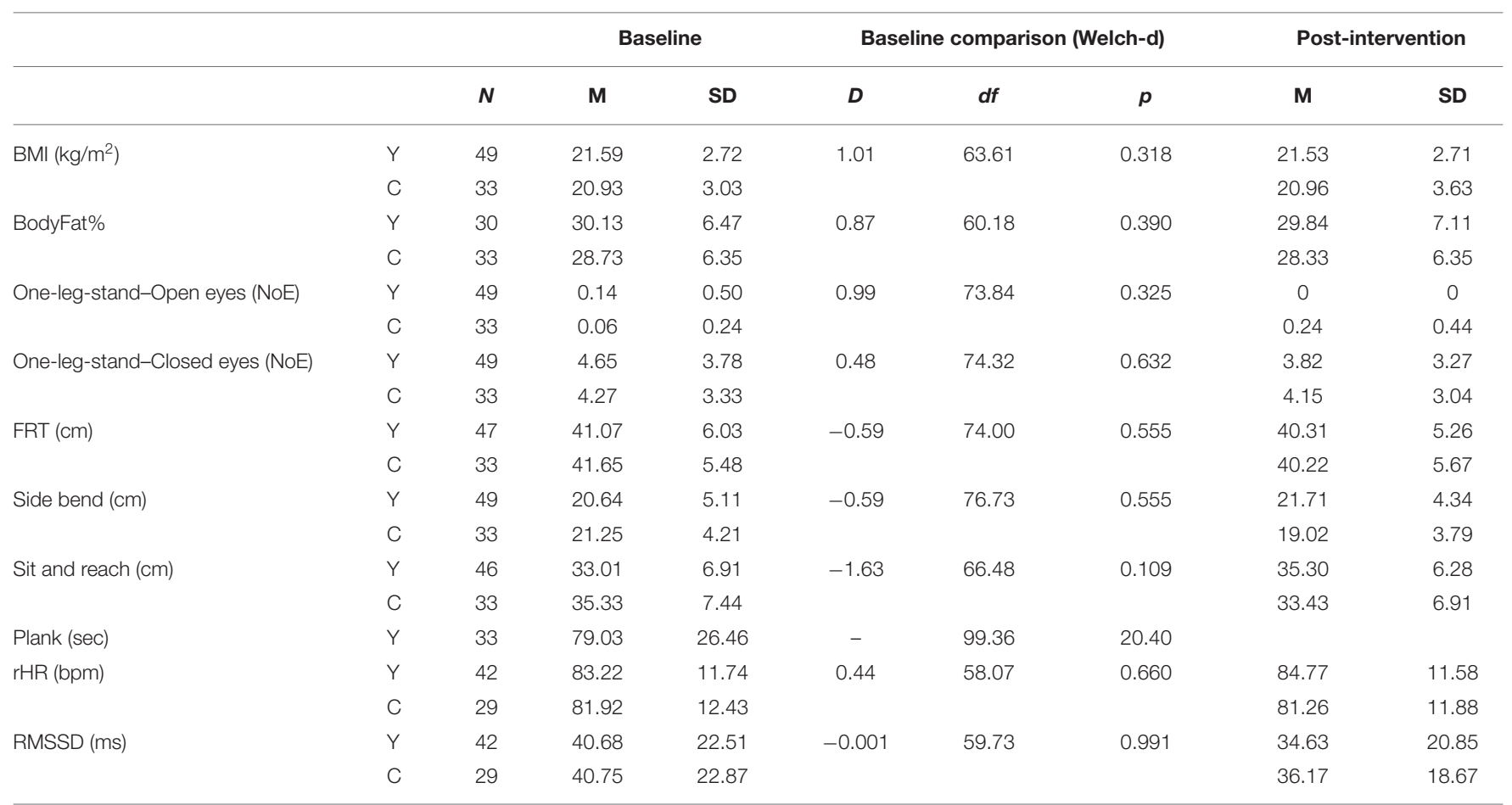

Y, Yoga; C, Control; NoE, Number of Errors; FRT, Functional reach test; $r H R$, resting HR.

Results of the $2 \times 2$ mixed ANOVAs for the physiological variables are presented in Table 3.

No interaction effect emerged in resting HR and RMSSD; $\mathrm{BF}_{10}$ values indicated the superiority of the null hypothesis.

Finally, average HR and energy consumption during 90-minlong yoga classes showed the following results: $A v g H R=93.39$ \pm 9.78 bpm, min-max: $69.40-111.57$; $k c a l=195.83 \pm 61.72$, min-max: 76.63-348.71 (an average of all classes).

\section{Discussion}

The present intervention study indicates that even a 10-session long beginner level hatha yoga training conducted on a weekly basis can result in improvements in balance, flexibility, and core muscle strength. However, it does not impact BMI, body fat percentage, resting heart rate and heart rate variability.

Studies which investigated BMI previously and reported a decrease in the outcomes involved a more frequent yoga training, e.g., daily yoga for 1 month (29), or 3-6 times/week training for 8 weeks (28). Average BMI of the participants in these two studies belonged to the overweight category $(26.4 \pm 2.5$ and $28.4 \pm 5.3$, respectively). In contrast, the present intervention included a weekly setting of 10 yoga sessions, furthermore, participants had normal BMI at the beginning of the course. Thus, it can be suggested that changes in BMI may occur with more frequent than weekly practice, and/or after more than 10 sessions and supposedly among obese people. The latter assumption is also strengthened by the results of a systematic review (68). Besides, average energy consumption of a yoga class of the present investigation was $195 \mathrm{kcal}$ (see later).
Thus, we can also assume that for measurable changes in BMI greater exercise intensity and energy consumption are needed. Concerning body fat percentage, the present results did not show significant changes in this measure, either. This is line with the outcomes of Tran and colleagues (31) who similarly investigated young healthy adults and reported null findings. The above-mentioned review (68) also denotes the lack of effect of hatha yoga practice on body fat percentage compared to usual care, exercise, or lifestyle modification. In contrast, two studies reported a significant decrease in body fat percentage $(30,36)$. However, one of those (30) investigated overweight participants, and the other one (36) found significant changes in two elder subgroups (30-39 and 40-49 years) with higher than normal body fat percentage, but not in young participants (20-29 years) with normal body fat percentage. Furthermore, another study investigating the effects of a 12 -week long (3 times/week) power yoga training reported significant decrease in body fat percentage among healthy middle-aged women (33). In summary, a decrease in body fat percentage might occur among elder and/or overweight participants with more intense yoga practice, but changes in body fat is not probable among healthy young adults after a short and less intense intervention.

Yoga participants of the present study showed a significant improvement in balance measured by the one-leg-stand with open eyes test compared to the control group. No changes measured by the one-leg-stand with closed eyes and FRT were found. Former studies $(33,34,38)$ applying one-leg-stand with open or/and closed eyes reported significant betterment in balance, however they included more frequent and/or longer 
TABLE 2 | Results of the $2 \times 2$ ANOVAs (both frequentist and Bayesian) for the physical variables.

\begin{tabular}{|c|c|c|c|c|c|}
\hline & & $F(d f)$ & $p$ & $\eta_{p}^{2}$ & $\mathrm{BF}_{10}$ \\
\hline \multirow[t]{3}{*}{ BMl } & Group & $0.890(1,80)$ & 0.348 & 0.011 & 0.651 \\
\hline & Time & $0.009(1,80)$ & 0.924 & $<0.001$ & 0.170 \\
\hline & Group*time & $0.076(1,80)$ & 0.783 & $<0.001$ & 0.288 \\
\hline \multirow[t]{3}{*}{ BodyFat\% } & Group & $0.790(1,61)$ & 0.378 & 0.013 & 0.794 \\
\hline & Time & $1.792(1,61)$ & 0.186 & 0.029 & 0.433 \\
\hline & Group^time & $0.041(1,61)$ & 0.839 & $<0.001$ & 0.298 \\
\hline \multirow{3}{*}{$\begin{array}{l}\text { One-leg-stand- } \\
\text { Open eyes }\end{array}$} & Group & $1.930(1,80)$ & 0.169 & 0.024 & 0.407 \\
\hline & Time & $0.127(1,80)$ & 0.723 & 0.002 & 0.168 \\
\hline & Group*time & $3.35(1,80)$ & $0.004^{\star \star}$ & 0.099 & 17.807 \\
\hline \multirow{3}{*}{$\begin{array}{l}\text { One-leg-stand- } \\
\text { Closed eyes }\end{array}$} & Group & $0.001(1,80)$ & 0.972 & $<0.001$ & 0.255 \\
\hline & Time & $1.397(1,80)$ & 0.241 & 0.017 & 0.417 \\
\hline & Group*time & $0.779(1,80)$ & 0.380 & 0.010 & 0.318 \\
\hline \multirow[t]{3}{*}{ FRT } & Group & $0.053(1,78)$ & 0.818 & $<0.001$ & 0.249 \\
\hline & Time & $2.428(1,78)$ & 0.123 & 0.030 & 0.469 \\
\hline & Group*time & $0.229(1,78)$ & 0.633 & 0.003 & 0.251 \\
\hline \multirow[t]{3}{*}{ Side bend } & Group & $1.407(1,80)$ & 0.239 & 0.017 & 0.473 \\
\hline & Time & $1.351(1,80)$ & 0.249 & 0.017 & 0.191 \\
\hline & Group*time & $11.121(1,80)$ & $0.001^{\star *}$ & 0.122 & 22.828 \\
\hline \multirow[t]{3}{*}{ Sit and reach } & Group & $0.021(1,77)$ & 0.884 & $<0.001$ & 0.415 \\
\hline & Time & $0.179(1,77)$ & 0.673 & 0.002 & 0.285 \\
\hline & Group*time & $20.779(1,77)$ & $<0.001^{* \star \star}$ & 0.213 & 1029.277 \\
\hline
\end{tabular}

${ }^{\star \star} p<0.01 .{ }^{\star \star \star} p<0.001$. FRT, Functional reach test.

TABLE 3 | Results of the $2 \times 2$ ANOVAs (both frequentist and Bayesian) for the cardiovascular variables.

\begin{tabular}{llcccc}
\hline & & $\boldsymbol{F}(\boldsymbol{d} \boldsymbol{f})$ & $\boldsymbol{p}$ & $\eta_{\boldsymbol{p}}^{2}$ & $\mathbf{B F}_{\mathbf{1 0}}$ \\
\hline rHR & Group & $0.888(1,69)$ & 0.349 & 0.013 & 0.455 \\
& Time & $0.118(1,69)$ & 0.732 & 0.002 & 0.200 \\
& Group*time & $0.738(1,69)$ & 0.393 & 0.011 & 0.317 \\
& Group & $0.033(1,69)$ & 0.856 & $<0.001$ & 0.275 \\
& Time & $3.859(1,69)$ & 0.054 & 0.053 & 1.177 \\
& Group*time & $0.074(1,69)$ & 0.787 & 0.001 & 0.264 \\
\hline
\end{tabular}

$r H R$, resting HR.

yoga programs. Similarly, the majority of the studies summarized by a systematic review (32) signified favorable outcomes, thus it can be concluded that 10 weekly sessions of yoga practice are sufficient to result in improvement of static balance with open eyes. However, for betterment in balance with closed eyes presumably longer or more intense yoga program might be needed. FRT, which similarly assesses static balance, can be rather noted as a measure of balance frailty (physical frailty) which shows moderate to strong negative association with age (69). Since the present investigation examined healthy young women, the differentiation of FRT might not be adequate enough among them to evaluate balance as a form of physical fitness. Nevertheless, it can also be proposed that 10 weekly session are not sufficient to register significant improvement in functional reach. Anyhow, improvement in balance through yoga in young ages is not only a sign of physical fitness but it can be a form of prevention of risks concerning falling in elderly ages (70).

Concerning flexibility, significant interaction effect in the sit and reach test and the side bend test showed that flexibility of yoga participants increased while it decreased in the control group at the end of the intervention. This is in line with the previous findings of Van Puymbroeck et al. (71). Compared to a light exercise group, improvements in the same flexibility tests were reported after an 8-week long (2 times/week) hatha yoga program (71). Other yoga studies investigating flexibility also found favorable outcomes in diverse male samples, like college athletes (34), preadolescent boys (72) and healthy men of various age groups (36). However, all of these studies $(34,36,72)$ used more frequent interventions than the present one. According to our results, we can propose that even a weekly setting of yoga practice is sufficient to evoke improvements in flexibility. This is supported by Amin and Goddman (35) who found significant improvements in pliability with weekly sessions of yoga after 6 weeks. However, in that study (35) asanas were purposely selected to improve strength and flexibility.

Yoga participants showed increased core muscle strength measured by the plank test. Data of control participants were not available in this measure, however the large effect size and the high probability indicated by the Bayes Factor strongly support the significance of this change. Similarly, previous studies showed positive outcomes in core muscle strength after yoga interventions of various intensity (38-40). Two review articles $(37,73)$, furthermore, denoted the relevance of specific yoga postures for strengthening core muscles. It can be concluded that weekly regularity of yoga practice results in enhanced core muscle strength. Furthermore, diverse yoga poses together with yoga breathing induce various activation magnitudes of core muscles (included diaphragm that regulates intra-abdominal pressure and trunk stabilization), which is proposed to be considered by planning proper yoga interventions (73-75).

Regarding cardiovascular outcomes, the present study did not find significant changes in HR and HRV after the 10-session long intervention. As cardiovascular activation caused by the yoga classes was of slight intensity (see below), this finding is not surprising. Also, it is line with the findings of Bidwell et al. (43) who did not report differences in HR and HRV measures between the yoga and the control group after a 10-week long yoga training. In contrast, a systematic review (44) revealed evidence for effects of yoga on HR. However, with one exception of all the 19 included randomized controlled trials investigated longer and/or more frequent yoga programs. Concerning HRV, two recent studies $(45,46)$ also reported positive outcomes, however both applied longer yoga interventions. Thus, we can assume that although yoga may affect $H R$ and $H R V$ positively, 10 weekly sessions are not sufficient to evoke such changes.

According to the descriptive statistics of average heart rate and energy consumption, we can denote, that the average heart rate during beginner level hatha yoga classes (inclusive short body and breath focus, as well as an $\sim 8-10$ min lying relaxation) was $93.39 \pm 9.78 \mathrm{bpm}$ (min-max: 69.40-111.57), and average energy 
consumption was $195.83 \pm 61.72 \mathrm{kcal}$ (min-max: 76.63-348.71). Cowen and Adams (76) investigated heart rate during different styles of yoga classes of $80 \mathrm{~min}$. They reported average heart rate during astanga yoga $95.18 \pm 12.80$, hatha yoga $80.17 \pm 9.32$, and gentle yoga $74.49 \pm 7.41 \mathrm{bpm}$ (76). Another study (77) reported $131 \pm 14 \mathrm{bpm}$ as average heart rate during a $45 \mathrm{~min}$ long power yoga class. A relatively recent study (78) showed that average heart rate of vinyasa yoga participant were $109.6 \pm 18.0 \mathrm{bpm}$ during a 60-min long class, and energy consumption were 273.8 $\pm 78.0 \mathrm{kcal}$. Compared to these previous results, yoga classes of the present intervention although beginner level, were around medium level in intensity among yoga styles.

It can be concluded that weekly setting of 10 beginner level traditional hatha yoga classes $(1.5 \mathrm{~h}$ each) can result in significant positive changes in balance, flexibility, and core muscle strength in healthy female adults. However, it does not lead to changes in BMI, body fat percentage, and resting HR and HRV. Regarding BMI and body fat percentage, positive changes might be expected only in overweight population or with more intense yoga practices. Changes in resting HR and HRV supposedly occur only with longer and/or more intense yoga intervention. Concerning descriptive data of average heart rate and energy consumption during yoga classes, we can state that beginner level hatha yoga classes show medium intensity among yoga classes, and might be an appropriate form of exercise to meet some public health guidelines (78). All in all, we can conclude that a beginner level of hatha yoga program of 10 weekly sessions can result in beneficial physical health outcomes.

For future studies, we recommend the inclusion of various populations with the same yoga intervention setting to explore whether current results can be generalized across genders, different age and health groups. Besides, we propose to specifically investigate the advantageous effects of hatha yoga practices compared to other physical exercises. For that, the use of the terminology of gymnastics during yoga practice could be applied. This would provide a better understanding of yoga movements for those who are not familiar with yoga terminology (e.g., most coaches and sport scientists), furthermore, it could enhance the possibility to capture the exact effects of yoga exercises beyond terminology. However, for some specific aspects of yoga practice, such as particular poses, movements, gestures, breathing patterns, or attentional focus, this might be a difficult task. Nevertheless, the use of terminology of gymnastics in yoga could aid the proliferation of the beneficial physical effects of hatha yoga in such, that it might bring it closer to a wide circle of physical education teachers and sports professionals.

\section{Limitations}

The sample of this study was restricted to young female participants. As further limitations we must mention the unbalanced sample size, the relatively large drop-out rate and lack of randomization of the design. However, to improve methodology, strict inclusion criteria for controlling potential confounding variables were applied (e.g., physical activity level in the previous months was measured; participants were not allowed to begin any new physical activities or body focus related activities beyond the current study; practicing yoga at home was not allowed). At the end of the intervention, participants were asked about their physical activity during the study period, however, it was not investigated by more precise measures. Future studies are proposed to control for this potential influencing factor with more accurate assessment, such as weekly activity tracking. Furthermore, we have to mention the lack of control data concerning plank test. During measurements, tests for interoception were also applied, among those the waterload test could have interfered with the usage of plank test. Thus, plank test was scheduled for the first and the last yoga classes. Lastly, it is relevant to mention that the control group did not received any intervention. However, main goal of the present study was not to assess the effectiveness of yoga practice compared to other physical activities, but to investigate whether weekly setting of a short beginner level yoga course can result in beneficial physical and physiological health outcomes. Nevertheless, attention received by the participants may have affected the results, thus present findings are restricted to face-to-face yoga practice, but might not be valid for home practice with recorded teachings. Potential biases during physical measurements before and after the training were minimized. Research assistants who conducted the measurements were blind to the group of the participants. However, motivations and expectations of participants were not monitored, which is suggested to do so in future studies.

\section{CONCLUSIONS}

Present outcomes indicate that weekly setting of a beginner hatha yoga training of ten $1.5 \mathrm{~h}$ long sessions causes improvements in balance, flexibility, and core muscle strength, but does not affect BMI, body fat percentage, resting heart rate, and heart rate variability in healthy young women. It can be concluded that weekly frequency of yoga intervention is adequate for beneficial changes in certain aspects of physical fitness, however for betterment in physiological, especially cardiovascular makers higher weekly frequency and/or longer time of training is needed. The relevance of these findings accords with the conclusions of Tolnai et al. (53), that weekly training is beneficial for those who cannot afford more leisure time than this for physical activity. However, engagement in regular physical activity might increase over time as beneficial outcomes occur, and the process might be able to end in a virtuous circle.

\section{DATA AVAILABILITY STATEMENT}

The raw data supporting the conclusions of this article will be made available by the authors, without undue reservation.

\section{ETHICS STATEMENT}

The studies involving human participants were reviewed and approved by Research Ethics Committee of the Faculty 
of Education and Psychology at ELTE Eötvös Loránd University, Budapest, Hungary. The patients/participants provided their written informed consent to participate in this study.

\section{AUTHOR CONTRIBUTIONS}

JK processed heart rate data. $\mathrm{BC}$ and $\mathrm{FK}$ processed all other data and performed the statistical analyses. BC wrote the first draft of the manuscript. RS suggested major improvements on it. All authors contributed to the assessment of data, read and commented on the last version of the manuscript, and conception and design of the study.

\section{REFERENCES}

1. Baktay E. A diadalmas jóga. Rádzsa jóga; a megismerés és önuralom tana. (The Triumphant Yoga. Raja Yoga; The Doctrine of Cognition and Self-Control). Szeged: Szukits Könyvkiadó (1992).

2. Iyengar BKS. Light on Yoga. London: The Aquarian Press (1991).

3. Satyananda Saraswati S. Four Chapters on Freedom. Commentary on the Yoga Sutras of Sage Patanjali. Munger: Yoga Publications Trust (2013).

4. Impett EA, Daubenmier JJ, Hirschman AL. Minding the body: yoga, embodiment, and well-being. Sexual Res Social Policy. (2006) 3:3948. doi: 10.1525/srsp.2006.3.4.39

5. Kaczvinszky J. Kelet világossága III. Misztikus Yoga. (Light of the East III. Mystical Yoga). Budapest: Hindy András Könyvkiadó (1943).

6. Kaczvinszky J. Kelet világossága I. Bevezetés a yogába. (Light of the East I. Introduction to Yoga). Budapest: Kötet Kiadó (1994).

7. Kaczvinszky J. Kelet világossága II. Gyakorlati Yoga. (Light of the East II. Practical Yoga). Budapest: Kötet Kiadó (1995).

8. Weninger A. A keleti jóga. (The Oriental Yoga). Budapest: MÉDIA Kiadói Iroda (1987).

9. Weninger A. Jóga a mindennapokban. (Yoga in Everyday Life). Budapest: Nótárius Kiadó GMK (1991).

10. Ross A, Thomas S. The health benefits of yoga and exercise: A review of comparison studies. I Alt Complement Med. (2010) 16:312. doi: 10.1089/acm.2009.0044

11. Park CL, Elwy AR, Maiya M, Sarkin AJ, Riley KE, Eisen SV, et al. The Essential Properties of Yoga Questionnaire (EPYQ): psychometric properties. Int J Yoga Therap. (2018) 28:23-38. doi: 10.17761/2018-0 0016R2

12. Devereux G. The Elements of Yoga. London: Element Books Ltd. (1994).

13. Govindaraj R, Karmani S, Varambally S, Gangadhar BN. Yoga and physical exercise-a review and comparison. Int Rev Psychiatry. (2016) 28:24253. doi: 10.3109/09540261.2016.1160878

14. Veda Bharati S. Philosophy of Hatha Yoga. Allahabad: Himalayan Institute India. (1985).

15. Yesudian S, Haich E. Sport és jóga. Magyar Világ Kiadó (1992).

16. Mehling WE, Wrubel J, Daubenmier JJ, Price CJ, Kerr CE, Silow T, et al. Body awareness: a phenomenological inquiry into the common ground of mind-body therapies. Philos Ethics Human Med. (2011) 6:6. doi: 10.1186/1747-5341-6-6

17. Patwardhan AR. Yoga research and public health: is research aligned with the stakeholders' needs? J Prim Care Community Health. (2017) 8:316. doi: $10.1177 / 2150131916664682$

18. Brown DHK. Seeking spirituality through physicality in schools: learning from 'Eastern movement forms'. Int J Child Spirit. (2013) 18:3045. doi: 10.1080/1364436X.2013.776521

\section{FUNDING}

This research was supported by the Hungarian National Scientific Research Fund (Országos Tudományos Kutatási Alapprogramok, OTKA K 124132).

\section{ACKNOWLEDGMENTS}

The authors thank their several colleagues for their contribution to data collection.

\section{SUPPLEMENTARY MATERIAL}

The Supplementary Material for this article can be found online at: https://www.frontiersin.org/articles/10.3389/fpubh. 2021.702793/full\#supplementary-material

19. Lu C, Tito JM, Kentel JA. Eastern Movement Disciplines (EMDs) and mindfulness: a new path to subjective knowledge in western physical education. Quest. (2009) 61:353-70. doi: 10.1080/00336297.2009.10483621

20. Field T. Yoga research review. Complement Ther Clin Pract. (2016) 24:14561. doi: 10.1016/j.ctcp.2016.06.005

21. Raub JA. Psychophysiologic effects of Hatha Yoga on musculoskeletal and cardiopulmonary function: a literature review. J Alt Compl Med. (2002) 8:797-812. doi: 10.1089/10755530260511810

22. Büssing A, Michalsen A, Khalsa SBS, Telles S, Sherman KJ. Effects of yoga on mental and physical health: a short summary of reviews. Evid Based Compl Alt Med. (2012) 2012:165410. doi: 10.1155/2012/165410

23. Dwivedi S, Tyagi P. Yoga as a health promotion lifestyle tool. Indian J Med Special. (2016) 7:29-34. doi: 10.17354/ijss/2017/312

24. Hendriks T, de Jong J, Cramer H. The effects of yoga on positive mental health among healthy adults: a systematic review and meta-analysis. J Alt Compl Med. (2017) 23:505-17. doi: 10.1089/acm.2016.0334

25. Domingues RB. Modern postural yoga as a mental health promoting tool: a systematic review. Complement Ther Clin Pract. (2018) 31:24855. doi: 10.1016/j.ctcp.2018.03.002

26. Sengupta P. Health impacts of yoga and pranayama: a state-of-the-art review. Int J Prev Med. (2012) 3:444-58. doi: 10.13016/lxqd-lc0o

27. Roland KP, Jakobi JM, Jones GR. Does yoga engender fitness in older adults? A critical review. J Aging Phys Activity. (2011) 19:6279. doi: 10.1123/japa.19.1.62

28. McDermott KA, Rao MR, Nagarathna R, Murphy EJ, Burke A, Nagendra $\mathrm{RH}$, et al. A yoga intervention for type 2 diabetes risk reduction: a pilot randomized controlled trial. BMC Complement Altern Med. (2014) 14:212. doi: 10.1186/1472-6882-14-212

29. Chauhan A, Semwal DK, Mishra SP, Semwal RB. Yoga practice improves the body mass index and blood pressure: a randomized controlled trial. Int J Yoga. (2017) 10:103-6. doi: 10.4103/ijoy.IJOY_46_16

30. Pandit DP, Upadhyah A, Goyal P, Sharma D. Effect of short term yoga on body weight, BMI, body fat percentage \& blood pressure. Indian J Clin Anat Physiol. (2019) 6:179-82. doi: 10.18231/j.ijcap.2019.040

31. Tran MD, Holly RG, Lashbrook J, Amsterdam EA. Effects of Hatha yoga practice on the health-related aspects of physical fitness. Prev Cardiol. (2001) 4:165-70. doi: 10.1111/j.1520-037X.2001.00542.x

32. Jeter PE, Nkodo A-F, Moonaz SH, Dagnelie G. A systematic review of yoga for balance in a healthy population. J Alter Complement Med. (2014) 20:22132. doi: 10.1089/acm.2013.0378

33. Jin HM, Kim SY, Moon H. Changes in muscular strength, balance, and body composition in middle-aged women with power yoga. FASEB J. (2016) 30(1 Supplement):1240.7. doi: 10.1096/fasebj.30.1_supplement.1240.7

34. Polsgrove MJ, Eggleston BM, Lockyer RJ. Impact of 10-weeks of yoga practice on flexibility and balance of college athletes. Int J Yoga. (2016) 9:27. doi: 10.4103/0973-6131.171710 
35. Amin DJ, Goddman M. The effects of selected asanas in Iyengar yoga on flexibility: pilot study. J Bodyw Mov Ther. (2014) 18:399404. doi: 10.1016/j.jbmt.2013.11.008

36. Halder K, Chatterjee A, Pal R, Tomer OS, Saha M. Age related differences of selected Hatha yoga practices on anthropometric characteristics, muscular strength and flexibility of healthy individuals. Int J Yoga. (2015) 8:3746. doi: 10.4103/0973-6131.146057

37. Modak P. A comprehensive review of yoga and core strength: strengthening core muscles as important method for injury prevention (lower back pain) and performance enhancement in sports. 19th International Conference on Sport, Exercise and Health Sciences, Vancouver, Canada.

38. Kumar S, Prasad S, Balakrishnan B, Muthukumaraswamy K, Ganesan M. Effects of Isha Hatha Yoga on core stability and standing balance. Adv Mind Body Med. (2016) 30:4-10.

39. Murugan M, Durai C. Influence of asana with Surya Namaskar practices on core strength among intercollegiate cricket players. Int J Yogic Human Movement Sports Sci. (2019) 4:627-8.

40. Radhakrishnan G. Effect of static asanas practices on core strength and balance among college students. Int J Yogic Human Movement Sports Sci. (2019) 4:992-4.

41. Schmalzl, L., Powers, C., and Henje Blom, E. (2015). Neurophysiological and neurocognitive mechanisms underlying the effects of yoga-based practices: Towards a comprehensive theoretical framework. Front Human Neurosci. 9. doi: 10.3389/fnhum.2015.00235

42. Tyagi A, Cohen M. Yoga and heart rate variability: a comprehensive review of the literature. Int J Yoga. (2016) 9:97-113. doi: 10.4103/0973-6131.183712

43. Bidwell AJ, Yazel B, Davin D, Fairchild TJ, Kanaley JA. Yoga training improves quality of life in women with asthma. J Alter Complement Med. (2012) 18:749-55. doi: 10.1089/acm.2011.0079

44. Cramer H, Lauche R, Haller H, Steckhan N, Michalsen A, Dobos G. Effects of yoga on cardiovascular disease risk factors: a systematic review and meta-analysis. Int J Cardiol. (2014) 173:170-83. doi: 10.1016/j.ijcard.2014. 02.017

45. Ganesan S, Gaur GS, Negi VS, Sharma VK, Pal GK. Effect of yoga therapy on disease activity, inflammatory markers, and heart rate variability in patients with rheumatoid arthritis. J Alter Complement Med. (2020) 26:5017. doi: $10.1089 / \mathrm{acm} .2019 .0228$

46. Odynets T, Briskin Y, Todorova V, Tyshchenko V, Bondarenko O. Effect of yoga in the modulation of heart rate variability in patients with breast cancer. Adv Rehabil. (2019) 33:5-11. doi: 10.5114/areh.2019. 89821

47. Elwy AR, Groessl EJ, Eisen SV, Riley KE, Maiya M, Lee JP, et al. A systematic scoping review of yoga intervention components and study quality. Am J Prev Med. (2014) 47:220-32. doi: 10.1016/j.amepre.2014.03.012

48. Park CL, Groessl E, Maiya M, Sarkin A, Eisen SV, Riley K, et al. Comparison groups in yoga research: A systematic review and critical evaluation of the literature. Complement Ther Med. (2014) 22:9209. doi: 10.1016/j.ctim.2014.08.008

49. Andysz A, Merecz D, Wójcik A, Swiatkowska B, Sierocka K, Najder A. Effect of a 10-week yoga programme on the quality of life of women after breast cancer surgery. Menopause Rev. (2014) 13:186-93. doi: 10.5114/pm.2014. 43823

50. Bilderbeck AC, Farias M, Brazil IA, Jakobowitz S, Wikholm C. Participation in a 10-week course of yoga improves behavioural control and decreases psychological distress in a prison population. J Psychiatr Res. (2013) 47:143845. doi: 10.1016/j.jpsychires.2013.06.014

51. Smith C, Hancock H, Blake-Mortimer J, Eckert K. A randomised comparative trial of yoga and relaxation to reduce stress and anxiety. Complement Ther Med. (2007) 15:77-83. doi: 10.1016/j.ctim.2006.05.001

52. Garner M, Reith W, Krick C. 10-week Hatha Yoga increases right hippocampal density compared to active and passive control groups: a controlled structural cMRI study. J Neuroimag Psychiatry Neurol. (2019) 04:27. doi: 10.17756/jnpn.2019-027

53. Tolnai N, Szabó Z, Köteles F, Szabo A. Physical and psychological benefits of once-a-week Pilates exercises in young sedentary women: a 10-week longitudinal study. Physiol Behav. (2016) 163:211-8. doi: 10.1016/j.physbeh.2016.05.025
54. Satyananda Saraswati S. Asana Pranayama Mudra Bandha. Munger: Yoga Publications Trust (2002).

55. Csala B, Ferentzi E, Tihanyi BT, Drew R, Köteles F. Verbal cuing is not the path to enlightenment. psychological effects of a 10-session Hatha Yoga practice. Front Psychol. (2020) 11:1375. doi: 10.3389/fpsyg.2020. 01375

56. Suni JH, Husu P, Rinne M. Fitness for Health: The ALPHA-FIT Test Battery for Adults Aged 18-69. Tester's Manual. European Union, DG Sanco. Tampere: UKK Institute for Health Promotion Research (2009).

57. Duncan PW, Weiner DK, Chandler J, Studenski S. Functional reach: a new clinical measure of balance. J Gerontol. (1990) 45:M192-197. doi: 10.1093/geronj/45.6.M192

58. Suni JH, Oja P, Miilunpalo SI, Pasanen ME, Vuori IM, Bös K. Healthrelated fitness test battery for adults: Associations with perceived health, mobility, and back function and symptoms. Arch Phys Med Rehabil. (1998) 79:559-69. doi: 10.1016/S0003-9993(98)90073-9

59. Hoeger WW, Hopkins DR. A comparison of the sit and reach and the modified sit and reach in the measurement of flexibility in women. Res Q Exerc Sport. (1992) 63:191-5. doi: 10.1080/02701367.1992.106 07580

60. Strand SL, Hjelm J, Shoepe TC, Fajardo MA. Norms for an isometric muscle endurance test. J Hum Kinet. (2014) 40:93-102. doi: 10.2478/hukin-20140011

61. Parak J, Korhonen I. Accuracy of Firstbeat Bodyguard2 Beat-to-Beat Heart Rate Monitor. White Paper by Firstbeat Technologies Ltd. (2013). Available online at: http://www.firstbeat.com/userData/firstbeat/tiedostolataukset/ white_paper_bodyguard2_final.pdf (accessed September 15, 2015).

62. Bogdány T, Boros S, Szemerszky R, Köteles F. Validation of the Firstbeat TeamBelt and BodyGuard2 systems. Magyar Sporttudományi Szemle. (2016) 17:5-12.

63. Task Force of the European Society of Cardiology and the North American Society of Pacing and Electrophysiology. Heart rate variability: standards of measurement, physiological interpretation, and clinical use. Circulation. (1996) 93:1043-65. doi: 10.1161/01.CIR.93.5.1043

64. JASP Team. JASP (Version 0.12.2.0). (2020). Available online at: https://jaspstats.org/ (accessed Octiber 09, 2020).

65. Jarosz A, Wiley J. What are the odds? A practical guide to computing and reporting bayes factors. J Prob Solv. (2014) 7:1167. doi: 10.7771/1932-6246.1167

66. Dienes Z. Bayesian versus orthodox statistics: which side are you on? Persp Psychol Sci. (2011) 6:274-90. doi: 10.1177/17456916114 06920

67. Kline RB. Beyond Significance Testing. Statistics Reform in the Behavioral Sciences (2th Edition). Washington, DC: sAmerican Psychological Association (2013). doi: 10.1037/14136-000

68. Lauche R, Langhorst J, Lee MS, Dobos G, Cramer H. A systematic review and meta-analysis on the effects of yoga on weight-related outcomes. Prev Med. (2016) 87:213-32. doi: 10.1016/j.ypmed.2016. 03.013

69. Weiner DK, Duncan PW, Chandler J, Studenski SA. Functional reach: a marker of physical frailty. $J A m$ Geriatr Soc. (1992) 40:203-7. doi: 10.1111/j.1532-5415.1992.tb0 2068.x

70. Boros S, Csala B, Szilágyi E. Yoga practice for the elderly: good choice to avoid falls. J Exerc Sports Orthopedics. (2018) 5:1-4. doi: 10.15226/2374-6904/5/1/0 0166

71. Van Puymbroeck M, Schmid A, Shinew KJ, Hsieh P-C. Influence of Hatha yoga on physical activity constraints, physical fitness, and body image of breast cancer survivors: a pilot study. Int $J$ Yoga Therapy. (2011) 1:49-60. doi: 10.17761/ijyt.21.1.n852143rv21 x188u

72. Nayek B, Chatterjee K. Effect of 6-weeks yoga and aerobic exercise on muscular strength and flexibility of pre- adolescence students. Int J Yogic Human Movement Sports Sci. (2016) 1:12-6.

73. Rathore M, Trivedi S, Abraham J, Sinha MB. Anatomical correlation of core muscle activation in different yogic 
postures. Int J Yoga. (2017) 10:59-66. doi: 10.4103/0973-6131.2 05515

74. Akuthota V, Nadler SF. Core strengthening11No commercial party having a direct financial interest in the results of the research supporting this article has or will confer a benefit upon the author(s) or upon any organization with which the authors is/are associated. Arch Phys Med Rehabil. (2004) 85:86-92. doi: 10.1053/j.apmr.2003.12.005

75. Key J. 'The core': understanding it, and retraining its dysfunction. J Bodyw Mov Ther. (2013) 17:541-59. doi: 10.1016/j.jbmt.2013.03.012

76. Cowen VS, Adams TB. Heart rate in yoga asana practice: a comparison of styles. J Bodyw Mov Ther. (2007) 11:91-5. doi: 10.1016/j.jbmt.2006. 08.001

77. Schubert MM, Clark AS, De La Rosa AB, Newcomer SC. Heart rate and thermal responses to power yoga. Complement Ther Clin Pract. (2018) 32:1959. doi: 10.1016/j.ctcp.2018.07.003

78. Sherman SA, Rogers RJ, Davis KK, Minster RL, Creasy SA, Mullarkey NC, et al. Energy expenditure in vinyasa yoga versus walking. J Phys Act Health. (2017) 14:597-605. doi: 10.1123/jpah.2016-0548
Conflict of Interest: The authors declare that the research was conducted in the absence of any commercial or financial relationships that could be construed as a potential conflict of interest.

Publisher's Note: All claims expressed in this article are solely those of the authors and do not necessarily represent those of their affiliated organizations, or those of the publisher, the editors and the reviewers. Any product that may be evaluated in this article, or claim that may be made by its manufacturer, is not guaranteed or endorsed by the publisher.

Copyright (c) 2021 Csala, Szemerszky, Körmendi, Köteles and Boros. This is an open-access article distributed under the terms of the Creative Commons Attribution License (CC BY). The use, distribution or reproduction in other forums is permitted, provided the original author(s) and the copyright owner(s) are credited and that the original publication in this journal is cited, in accordance with accepted academic practice. No use, distribution or reproduction is permitted which does not comply with these terms. 